\title{
How Does User Social Network Improve Innovation Outcomes on a Virtual Innovation Platform? Evidence From LEGO Ideas Platform
}

\author{
Guijie Qi, School of Management, Shandong University, China \\ Linke Hou, Center for Economic Research, Shandong University, China \\ Jiali Chen, School of Management Engineering, Shandong Jianzhu University, China \\ Yikai Liang, School of Management Science and Engineering, Shandong University of Finance and Economics, China \\ iD https://orcid.org/0000-0002-8696-4446 \\ Qi Zhang, School of Economics, China Center for Economic Studies, Fudan University, China
}

\begin{abstract}
Previous studies demonstrate that online interactive relations can help improve users' innovation outcomes, yet few studies have investigated how they influence user innovation. This paper builds a social network based on users' online interactive relations in one virtual innovation platform (LEGO Ideas). It characterizes the online social network relations from both quantity and quality dimensions and examines their influencing paths on users' innovation outcomes (i.e., emotional support and information flow). The empirical results show that both the quantity and quality of online relations impose positive effects on innovation, yet in different ways. The quantity of online relations could bring users more positive emotions, whereas the quality of online relations could bring them with more useful information and knowledge. By examining the influencing paths, this paper contributes to the literature on how online relations influence innovation outcomes as well as provides practical suggestions for innovation platforms.
\end{abstract}

\section{KEYWORDS}

Emotional Support, Influencing Path, Information Flow, LEGO Ideas, Online Relations, Quality of Social Relations, Social Network, User Innovation

\section{INTRODUCTION}

With the rapid development of Web 2.0 in recent years, increasing numbers of enterprises have established their Internet-based platforms to attract customers' contributions to enterprise innovation. A virtual innovation platform is a place where users can propose new product design or innovative ideas directly to a specific company (Hwang et al., 2019). For example, Dell Group established the IdeaStorm to collect users' ideas and suggestions for improving product and production. Even the enterprises in developing countries, such as Haier Group in China, have also built the innovation platforms that which encourage domestic users to participate in their product innovation. For these 
enterprise-initiated innovation platforms, stimulating users to produce more and better innovation ideas is the key to success and sustainability (Liang et al., 2016).

Many scholars have investigated on how to improve the users' innovation outcomes from different perspectives, such as IT/IS design (Gharib et al., 2017; Islam \& Rahman, 2017), the platform boundary and openness design (Balka et al., 2014; Liang et al., 2016), the incentives for user participation and contribution (Frey et al., 2011; Baldus et al., 2015; Hossain, 2017), and the leader users identification (Jeppesen \& Laursen, 2009; Bulgurcu et al., 2018). Moreover, the popularity and usage of the social media in innovation platforms boosts a new perspective - the user interactions and relations (Kosonen et al., 2013; Hassan et al., 2019).

Many studies have shown that online interactive relations (e.g., friending or following others, voting or commenting on others' ideas) among individuals can help to improve user innovation, such as extending the duration of users' participation, contributing more knowledge (e.g., the reviews or comments) or ideas, and improving the quality of ideas (Blohm et al., 2011; Chen et al., 2012; Kosonen et al., 2013; Chan et al., 2015). Previous studies mostly investigate the online relations from quantity dimension (e.g., the number of followers/friends/commentators) (Wasko \& Faraj, 2005; Trier, 2008; Chen et al., 2012). Yet some recent studies use social network analysis to characterize the online relations from multiple dimensions (e.g., direction, quantity, strength, etc.) and explore their impacts on user innovation (Chan et al., 2015; Hwang et al., 2019; Rishika \& Ramaprasad, 2019). However, the literature has not demonstrated how these relations improve users' innovation outcomes and the different roles for the relations' multiple dimensions. It is necessary to explore the influencing path of social network relations on innovation outcomes under the context of virtual platforms. Only the influencing mechanism is figured out, the reasonable suggestions for platforms improving user innovation outcomes can be given.

According to social capital theory, one's social relations enable individuals in a social network to access and exchange useful resources from others, which would have an effect on their innovation outcomes (Fowler \& Christakis, 2010). Tsai and Ghoshal (1998) has confirmed that the resource exchange between departments in the intrafirm networks mediated the influence of social relations on departments' innovation performance. Thus, tracking the users' interactive behaviors and analyzing the contents of interactions shed the light on exploring the working mechanism of how users' online relations influence innovation outcomes. Recently, researchers have started to use big data to analyze the unstructured content (e.g., texts, images) generated by online users (Sapountzi \& Psannis, 2018). The common practices for the textual content analysis include keywords extraction (Stephen et al., 2016), topic and event detection (Vavliakis et al., 2012; Panagiotou et al., 2016), and sentiment analysis (Poria et al., 2016; Yu et al., 2016). The textual content analysis is able to track and analyze the textual contents of user interaction in order to explore the influencing paths of users' online relations on innovation outcomes.

In order to explore how users' online relations influence innovation outcomes, this study analyzes online relations multi-dimensionally (i.e., quantity \& quality) and investigates the influencing paths (i.e., emotional support $\&$ information flow) for each dimension. Apart from the quantity of online relations which is focused by previous studies, we argue that the role of the relations' quality should also be further explored. The quality of online relations could dramatically influence the quality of resource exchange among users and their innovation outcomes, yet few previous studies have pointed this out. Taking the LEGO Ideas platform as a context, this study builds a social network based on 2,043 users' two-way follow-up connections, which generates the accurate measures of both the quantity and quality of online relations. Firstly, we separately test the effects of the quality of users' relations in improving their innovation, controlling for the relations' quantity. Secondly, through mining the text content of users' interactions, we examine the mediation effects of emotional support $\&$ information flow for both the quantity and quality of online relations.

Through multiple regressions and the mediation test, we find both the quantity and quality of online relations have positive effects on innovation, yet in different ways. The increased number of 
online relations could help users generate more positive emotions, while the quality of these relations could provide users with more useful information and knowledge. This study makes contributions in several ways. It offers complementary insights to previous studies by analyzing the relations on multiple dimensions (i.e., quantity \& quality) and verifying the effect of relations' quality on user innovation. Moreover, this study contributes to the user innovation literature by examining the influencing paths of how online relations affect users' innovation, as well as the emotional support $\&$ information flow. This study also checks the difference in influencing paths between multiple dimensions (i.e., quantity \& quality) of social relations. Besides, it also gives some suggestions for virtual innovation platforms to improve innovation performance.

The rest of the paper is structured as follows. The next sections describe the relevant literature and hypotheses development respectively. Section Methodology presents the data for empirical analysis, the social network for LEGO innovation platform, as well as the empirical strategy. Section Empirical Results details the results of the empirical analysis and robustness checks. Finally, this paper summaries the main conclusions, and presents the contributions and implications.

\section{LITERATURE REVIEW}

\section{Social Capital Theory and Social Network Analysis}

The social capital theory is the foundation for understanding the relationship between social networks and innovation outcomes (Tsai \& Ghoshal, 1998). Lin (2002)—one of the representatives of social capital theory defines social capital as the valuable resource embedded in social networks, including both material resources (e.g., wealth) and symbolic resources (e.g., reputation, rights). These resources are possessed by others and can be borrowed or accessed by the focal individual through social relations. Individuals' social capital can help them to achieve specific goals (e.g., innovation), by enabling them to access useful resources from connected others. The social capital theory proposes that the social relation network one embedded in reflect one's social capital. Whether social capital can be created and mobilized depends on the reciprocal obligation in the society, that is, a social rule that the beneficiary who received resources would give back (Lin, 2002).

Meanwhile, the rise of social network analysis in recent decades provides the proper method to measure social capital and explore the effect of social network on individual performance. The social network analysis allows the social relationship and network to be measured and quantified (Wasserman \& Faust, 1994). Generally, the social network analysis is used to measure the structural and the relational dimensions of one's social capital. The structural dimension refers to individuals' social network location (e.g., connectivity, centrality, structural hole), which determines whom the individual can interact with and provides the advantages for the individuals to control innovative resources, information, and knowledge (Nahapiet \& Ghoshal, 1998). The closer to central or bridge position, the better innovation performance (Cross \& Cummings, 2004; Tan et al., 2015). The relational dimension refers to assets that are rooted in the social relations, such as interpersonal trust and trustworthiness, feelings of closeness or interpersonal solidarity, which influences what kind of resources that are within people's reach, and to what extent they could access them (Granovetter, 1973). Social network scholars usually use tie strength to measure the relational dimension and study its effects on innovation performance (McFadyen \& Cannella Jr., 2004; Chan et al., 2015).

\section{Online Relations in Virtual Innovation Platforms}

The virtual innovation platform provides an environment where innovators can interact freely. When the innovators with common interests and innovation intentions gather on one vitual platform, they are willing to make friends and interact with each other. Users can propose their innovative ideas on the platform, and others can browse them freely. One user can follow others when he/she is interested in or appreciates others' proposals (e.g., innovative ideas or suggestions, designing plans), without 
others' permission, and also can be followed by others. Once the follow-up ties are created, users can easily track the activities and proposals of their connections when they login to the innovation platform. Besides, users also can communicate with others about the proposals, through following, voting, or commenting on others' (Hwang et al., 2019). Thus, the interactive relations between users form the user social network.

The symmetry of follow-up relations results in three kinds of distinct ties - reciprocated, follower, and followee ties. Goes et al. (2014) focus on the ties of subscription, i.e., follower ties. They find that the one-way ties of following can affect users' review writing behavior by simply providing attentive ears. Furthermore, Rishika and Ramaprasad (2019) explore the heterogeneous effects of all these three kinds of ties in one social media community. They show that reciprocated ties exert the greatest influence on users' contribution behavior, followed by followee ties and then follower ties. Because the social influence varies across different types of ties. Several influencing mechanisms (e.g., information sharing, social learning, identity seeking, and reciprocity considerations) work simultaneously to facilitate a stronger influence over reciprocated ties.

In this study, we focus on reciprocated ties, i.e., the two-way follow-up connections between users. There are three reasons for this. First, if two users follow each other, it provides great convenience for them to track and interact with each other, share and exchange information freely through the Internet. Second, the two-way follow-up connections represent the existence of reciprocity. According to social capital theory, the reciprocal obligation is the cornerstone for accessing resource benefits in the social network. The two-way follow-up relations ensure the users' reciprocal intentions of exchanging resource. Third, the study of Rishika and Ramaprasad (2019) has verified the importance of reciprocated ties on users' behavior, which has greater influence than the one-way ties.

\section{User Social Network Relations and Innovation Outcomes}

Many researches have examined the positive effect of user social network relations on innovation outcomes, but mostly using a rough measure of these relations between innovators, such as the number of their online relations or interactions (e.g., "followers", "friends", "commentators") (Wasko \& Faraj, 2005; Trier, 2008; Chen et al., 2012). For example, Wasko and Faraj (2005) studied an online discussion forum and found that the individuals who have more direct social relations contribute more helpful knowledge. Similarly, Yang and Li (2016) examined the effect of social relations on knowledge outcomes (customer-generated content) and found that the number of social relations influences the knowledge outcomes, mediated by the norm of reciprocity and shared language.

A few recent studies start to explore the multi-dimensional online relations, mostly combined with social network analysis. For example, Chan et al. (2015) consider the users' relations from three aspects - direction, size, and strength, and explore their impacts on users' idea generation for each aspect. Rishika and Ramaprasad (2019) examine both the structural and relational properties of a user's social network. They find the influence of online network ties on users' contribution behaviors varies across reciprocated, follower, and followee ties, while tie strength among network ties amplify this influence. Hwang et al. (2019) study one specific dimension of user interaction - whether users interact with others on broad topic domains or not and find that generalists are more likely to create novel ideas than non-generalists. Though some studies have examined the online relations from some detail characteristics - the direction, size, strength, interaction broadness, etc., few investigated the quality aspect, which could also dramatically influence the quality of resource exchange among innovators and their innovation outcomes. Moreover, few studies demonstrate how online relations improve users' innovation outcomes as well as the influencing paths. More detailed characteristics of online user social network relations and the mechanism of how they affect user innovation also need further exploration (Kane et al., 2014). 


\section{HYPOTHESES DEVELOPMENT}

\section{Quantity and Quality of User Social Network Relations and Innovation Outcomes}

Thanks to the availability of users' interaction data on the innovation platform, the in-depth characterization of the online relations and user social network become possible. Therefore, this paper will investigate the user social network relations from both quantity and quality dimensions to construct explanatory factors for users' innovative outcomes.

At first, as what the scholars did in the previous studies, we measure users' social network relations from the quantity dimension. The online relations can bring users with identification and a bond to the virtual communities and platforms (Guo et al., 2017). When users identify with a group in terms of common goals and values and consider themselves an integral part of the group, they are likely to be active participants in the community (Tsai \& Bagozzi, 2014). Many studies claim that the social relationship is one of the main factors in influencing an individual's continuance usage and participation towards the ISs (e.g., innovation platform) (Huang et al., 2009; Lin \& Lu, 2011; Sun et al., 2014). Thus, online relations can enhance the user's participation and interactions with others. This would help users to share experience and information with each other and thus generate new creative ideas (Chiu et al., 2006). Chan et al. (2015) studied the users' ideation behaviors in the crowdsourcing community and demonstrated the significant impacts of users' online interactions on their subsequent ideas.

In the previous studies, there are two viewpoints on the relationships between quantity of social relations and innovation performance. Some scholars focus on the resource benefits (e.g., innovation knowledge, information, support) of the social relations and claim that the more relations would lead to better innovation performance (Tsai \& Ghoshal, 1998; Cross \& Cummings, 2004). However, some scholars demonstrate that the quantity of social relations and their performances show a curvilinear relationship (McFadyen \& Cannella Jr., 2004; Zhou et al., 2009; Lechner et al., 2010). They argue that relationships require time, energy, and attention to establish and maintain, therefore there is a limit to the number of productive relationships that any given person can maintain (Zucker et al., 1995). The greater the number of social relations that an individual must maintain, the less the effort the individual can put into innovation. Moreover, when the number of relations becomes large enough and exceed the optimize level, individuals are likely to experience information overload and redundancy. Thus, an increasing number of relations eventually lead to less new knowledge creation.

However, the online relations are quite different from the offline social relations (e.g., the friends or working relationships) which the previous studies generally focused on. Firstly, online social relations are costless and relatively easy to build and maintain, which just requires individuals move the mouse a bit or type some words with the keyboard. In the social media era, individuals are often involved in a great number of many kinds of online relations. They can use social media tools either to maintain old relationships or to make new friends and relations (Williams, 2006). Due to the costlessness of online relations, the numbers of one's social relations has been greatly expended. Secondly, the users have greater selectivity in establishing or cancelling online relations. Considering that the platforms can attracts users from all over the world, users can choose the individual who owns more diverse knowledge to interact with (Kane et al., 2014). A great number of online relations could not completely represent the information overload and redundancy. These features of online relations dramatically reduce the possibility of showing curvilinear relationship with user innovation performance. This paper proxy the quantity of a user's social network relations by the number of reciprocated ties, i.e., the two-way follow-up connections between users. Thus, we propose the following hypothesis:

H1: On the virtual innovation platform, the quantity of users' social network relations positively influences their innovation performance. 
Moreover, besides the quantity dimension, it is necessary to consider the relations from the quality dimension, which is often neglected by most stuides. Akcigit et al. (2018) have reported that the highquality interaction (cooperation with high-level innovators) in patent cooperation could improve the patent performance but the low-quality interaction (cooperation with low-level innovators) did the opposite. The quality of interactions can dramatically influence the quality of information sharing among innovators and their innovation outcomes.

For virtual innovation platforms, the quality dimension of online relations can also be identified by whether to interact with high-level innovators. We define a social tie connecting with a high-level innovator as a quality social tie, and otherwise as a common social tie. One way to know users' innovation level is to evaluate their past innovation outcomes (Ernst \& Brem, 2017; Pajo et al., 2017). For example, Dell's innovation platform - IdeaStorm allows users to give positive or negative tags to any idea, then those users whose ideas get more positive tags are deemed the high-level ones (Chen et al., 2012). Additionally, some platforms provide the rankings of innovators to specify the high-level ones.

Generally, high-level innovators possess more valuable innovation resources like abundant explicit and tacit knowledge, so the quality social tie can convey them to the focal user and inspire the latter to generate better ideas. Besides, the individuals in the social network are more likely to be influenced by the connected ones to change their attitudes or behaviors (Kilduff \& Tsai, 2003). The important members in the platform, who have high platform recognition (e.g., the proposals are appreciated or adopted by the platform) and high user recognition (e.g., a great number of followers), tend to have more power in social influence (Latané, 1981). Hence the ties connected with highlevel innovators can transfer a great sign and competition to produce better ideas to the focal user, which would strengthen the focal user's intention and behavior to improve innovation performance. Moreover, the greater the number of quality social ties is, the greater the social influence would be. Then this paper characterizes the quality of a user's social network relations by the share of quality social ties over the user's total ties. Thus, we propose the following hypothesis:

H2: On the virtual innovation platform, the quality of users' social network relations positively influences their innovation performance.

\section{The Mediation Effects of Emotional Support and Information Flow}

As one of the most important aspects of social capital, social relations enable individuals in the social networks to access and exchange useful resources from others. Tsai and Ghoshal (1998) study the social relations between the departments in the intrafirm network, and confirm that the resource exchange between departments mediates the influence of social relations on innovation outcomes of the focal department. The useful resources include information, product, personnel, and support from other departments. To find the influencing paths of how online relations enhance users' innovation outcomes, it is necessary to examine whether and how online users exchange resources and what kind of resources. Through tracking and analyzing the content of users' interactions, this paper proposes two main paths.

The first path is presumably emotional support. Through online interactions, users can give each other emotional support, e.g., encouragement and praise. This would intensify users' identification to the virtual innovation platform. Obtaining recognition intrinsically motivates users to participate the community activities (e.g., proposing innovative ideas) (Baldus et al., 2015; Hossain, 2017). Meanwhile, the user's recognition helps to create a virtual environment with cooperation and trust (Pai \& Tsai, 2016). The previous research showed that recognition and trust from others may drive users to share more tacit knowledge and contribute more novel ideas (Becerra et al., 2008; JanowiczPanjaitan \& Noorderhaven, 2009). 
Besides, encouragements from others would produce the user with positive emotions. According to the broaden-and-build theory of positive emotions, positive emotions can motivate individual to form a broaden mindset, which would promote individual to generate novel thinking patterns and creative actions (Fredrickson, 2004). Some studies have examined the emotion-creativity relationship and found that positive emotion can benefit creativity (Amabile et al., 2005; Choi et al., 2011), and consequently help to enhance individuals' innovation outcomes (Yuan \& Woodman, 2010). Thus, we propose the following mediation hypotheses:

H3: Emotional support mediates the effect of users' social relations on their innovation performance.

H3a: The quantity of users' social relations affects their innovation performance through the mediation of emotional support.

H3b: The quality of users' social relations affects their innovation performance through the mediation of emotional support.

The second path is the information flow between users. The online innovators can share information and knowledge through interactions, such as comments and replies. Possession and dissemination of new information are key factors in determining a user's desire to contribute, as users join online communities to obtain novel and interesting information (Zhu \& Zhang, 2010). Through online interactions, the tacit knowledge embedded in innovators is externalized to the explicit knowledge. The sharing and exchange of knowledge and information between users would promote knowledge creation (Van den Hooff \& de Leeuw van Weenen, 2004). Previous studies of innovation have shown that innovative ideas are often formed by rearranging or combining information and knowledge in new ways (Amar \& Juneja, 2008; Kohn et al., 2011). Thus, the more information the users accesses, the more likely the user contributes to innovation outcomes. Additionally, users also can learn about the process and role of proposing innovation ideas in the innovation platform through interactions, which helps mitigate a focal user's uncertainty associated with platform characteristics and increase the users' willingness to contribute ideas (Rishika \& Ramaprasad, 2019).

Moreover, some scholars pay attention to the novelty/redundancy of the information from social relations and their effects on innovation performance (Stephen et al., 2016). The more novelty information the users can access, the better their innovation performance. Generally, high-quality social ties tend to bring focal users more useful and novel knowledge and information, since the highlevel innovators have more valuable experience for producing better ideas. Overall, online relations can help users to acquire and learn more information, which would consequently improve innovative outcomes (Imran Muhammad, 2019). Thus, we propose the following mediation hypotheses:

H4: Information flow mediates the effect of users' social relations on their innovation performance.

H4a: The quantity of users' social relations affects their innovation performance through the mediation of information flow among users.

H4b: The quality of users' social relations affects their innovation performance through the mediation of information flow among users.

\section{METHODOLOGY}

\section{LEGO Ideas Platform and Data}

We use the LEGO Ideas platform (URL: ideas.lego.com) as the research context to investigate the user social network. Formally established in April 2014, it is one of the most successful online innovation platforms, aiming to collect innovative ideas from global Lego fans. Registered users can submit their ideas of original blocks models, and then collect supports to be voted as the best ones for commercialization. Until the end of 2019, the platform has attracted more than one million 
registered users, who contribute over thirty thousand original blocks models. And many blocks are commercialized and very popular with customers, such as WALL•E and LEGO Minecraft.

This paper chooses the users who submitted original ideas in 2017 as the research sample. All the data are crawled using Python program, including users' interactive activities, users' characteristics (i.e., users' platform age, the number of the ideas submitted, users' platform points and badges), and users' ideas (i.e., idea description, images of the blocks model, the number of the supports, comments, and views). After deleting data with missing values, a data set of 2,043 users with 3,961 ideas is created.

\section{User Social Network on LEGO Ideas Platform}

We define a two-way follow-up connection between users as a tie to build users' online social network. So, if two users follow each other, it provides great convenience for them to track and interact with each other through the LEGO platform or many other social media, since most of the users post their social media accounts (e.g., Linked-In, Facebook, Instagram) on their user pages. We then extract the "follow-up" items from users' interactive activities in the crawled data and use the social network analysis tool - Python NetworkX package to build the network ${ }^{1}$.

The procedures of building the network are as follows. Firstly, building a network with 2,043 sample users as the nodes and the follow-up connections between users as the edges. If user $\mathrm{A}$ follows user B, there will be a directed edge from node A to node B. Therefore, this original network is a directed multi-graph. Secondly, transforming the directed multi-graph into an undirected simplegraph. We drop the self-loops and non-reciprocal edges and convert multi reciprocal edges between two users to one undirected edge. Third, visualizing the undirected simple-graph and showcasing the user social network (see Figure 1). In the figure, 634 nodes have one or more edges, while 1409 nodes are isolated and mostly scattered in the outer circle. Moreover, the color of the node refers to the node degree - the total number of online relations built by the focal user.

\section{The Empirical Models and Variables}

This study focuses on the influence of social network relations on users' innovation performance. Firstly, this paper tests the effects of the relations' quantity and quality on innovation performance. The empirical models are specified as equation (1) and (2). Secondly, this paper respectively tests the mediation effects of emotional support and information flow when social network relations effect innovation performance:

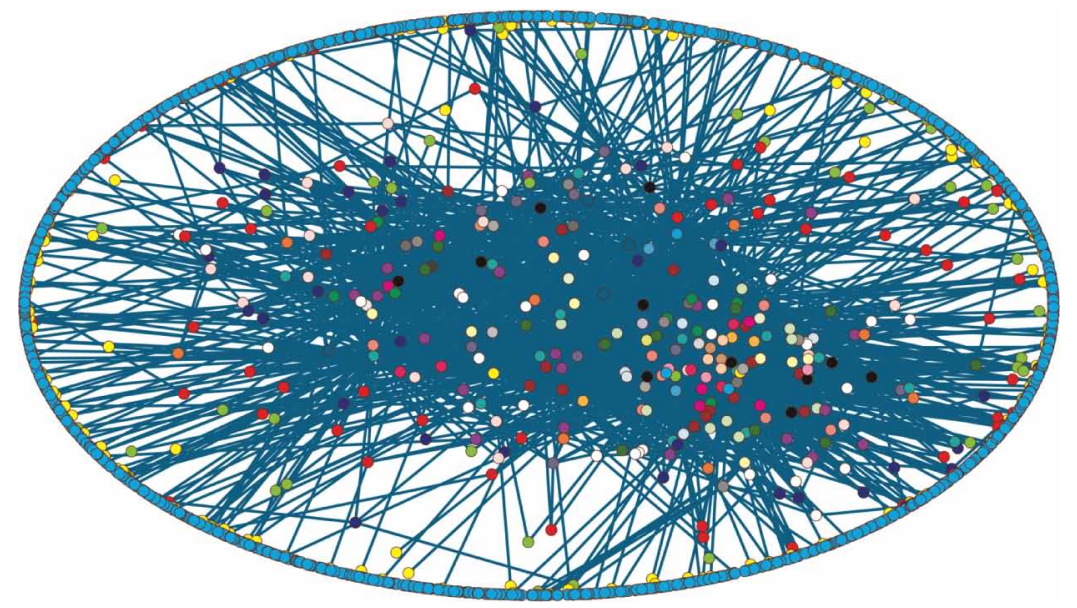




$$
\begin{aligned}
& Y_{i j}=\beta_{0}+\beta_{1} \text { Ntie }_{i}+\beta_{2} \text { Cuser }_{i}+\beta_{3} \text { Cidea }_{i j}+\beta_{4} \text { Time }_{i j}+\varepsilon_{i j} \\
& Y_{i j}=\beta_{0}+\beta_{1} \text { Ntie }_{i}+\beta_{2} \text { SQtie }_{i}+\beta_{3} \text { Cuser }_{i}+\beta_{4} \text { Cidea }_{i j}+\beta_{5} \text { Time }_{i j}+\varepsilon_{i j}
\end{aligned}
$$

In equation (1) and (2), $Y_{i j}$ is the performance of the idea $j$ submitted by the innovator $i$. Ntie and $S$ tie $_{i}$ refer to the quantity and quality of users' social network relations, respectively. The control variables include both the user characteristics $\left(\mathrm{Cuser}_{i}\right.$ ) and idea characteristics (Cidea $a_{i j}$ ). Additionally, we also include the time trend $\left(\right.$ Time $_{i j}$ ) to control for unobservable time-varying factors.

\section{Dependent Variable}

Some studies use peer evaluation on the user innovation platform to measure users' innovation performance. For example, Huang et al. (2014) use the number of votes for an idea as its performance measure. In the LEGO Ideas platform, better ideas tend to have more user supports. Thus, we measure the dependent variable of innovation performance (innovation) by the number of "support" votes for an idea, which should be a non-negative integer.

\section{Main Independent Variables}

We measure the quantity of user social network relations (Ntie) by the number of online social ties, which is also the user's node degree in the user social network. We measure the quality of user social network relations (SQtie) by the share of quality ties over a user's total social ties. To obtain quality ties, we first need to identify the high-level innovators. In the LEGO Ideas platform, the platform would award the " $1 \mathrm{~K}$ Badge" to the users with any idea receiving over 1,000 supports, who will be deemed as excellent innovators by the platform and users. Hence, we categorize users with " $1 \mathrm{~K}$ Badge" as high-level ones and otherwise as common ones. In practice, we use the Python NetworkX package to automatically count the number of quality ties and calculate its share. ${ }^{2}$

\section{Mediation Variables}

On the LEGO Ideas platform, users can post their comments about one idea on the innovators' pages, which is the common interaction among users. We collect the comments texts for each idea, and employ the text mining technology (i.e., sentiment analysis and unique words extraction) to retrieve measures of two mediators - emotional support \& information flow. For each idea, this paper analyzes all its comments texts. On the one hand, users will get active emotions from positive comments, hence we count "the number of positive comments" to measure the emotional support (emotion). On the other hand, users will obtain rich information from the comments' texts. According to Stephen et al. (2016), we adopt "the number of unique useful words in all texts" to measure the information flow (infor). Table 1 describes the main measures for the two variables, as well as their alternative measures.

\section{Control Variables}

Following the work of Hossain and Islam (2015), we choose control variables from two aspects: user characteristics and idea characteristics. For user characteristics, we measure the user's Innovative Experience by the number of ideas contributed by a user (Hwang et al., 2019). We proxy for the user's Innovation Level with a binary indicator of whether the user is a high-level innovator. Moreover, we construct the Social Tendency to assess whether a user tends to actively help or share their knowledge with others, as withholding knowledge would negatively affects one's creativity (Černe et al., 2014). In the LEGO Ideas platform, we retrieve the number of Socializer Badges owned by a user to gauge their Social Tendency. We also control for the user's Platform Age (Li et al., 2016). For idea characteristics, 
Table 1. The Measure of Emotional Support and Information Flow

\begin{tabular}{|c|c|c|c|}
\hline Variable & Notation & Main Measure & Another Measure \\
\hline emotional support & emotion & $\begin{array}{c}\text { 1. Calculate the sentiment score for } \\
\text { each comment using SentiStrength - } \\
\text { one popular sentiment analysis tool } \\
\text { (see Appendix A). } \\
\text { 2. Count the number of positive } \\
\text { comments. }\end{array}$ & $\begin{array}{c}\text { 1. Calculate the sentiment score for each } \\
\text { comment using SentiStrength. } \\
\text { 2. Sum the sentiment scores of all } \\
\text { comments. }\end{array}$ \\
\hline $\begin{array}{c}\text { information } \\
\text { flow }\end{array}$ & infor & $\begin{array}{c}\text { Count the number of unique useful } \\
\text { words in the whole comments texts } \\
\text { using Python (see Appendix B). }\end{array}$ & $\begin{array}{c}\text { Count the number of the unique noun } \\
\text { words in the whole comments texts } \\
\text { using Python. }\end{array}$ \\
\hline
\end{tabular}

we control for Number of Images, Number of Idea's Pageviews, and Idea Age, which are the common variables that may affect the supports of one idea (Li et al., 2016; Ma et al., 2019).

Given that the sample spans, which is a long period of 12 months from January 2017 to December 2017, users' innovation performance may be exposed to common unobservable time-varying shocks. Hence, we use the time to submit ideas (month) and the number of participants submitting ideas in the same month (num) to control for these time-varying factors (Hwang et al., 2019). Table 2 provides the descriptions of all variables, and Table 3 the summary statistics.

\section{EMPIRICAL RESULTS}

\section{The Effects of Social Ties on Innovation Performance}

Considering the dependent variable (innovation) is a count variable, Poisson regression is used. Since one user can submit multiple ideas, which might cause potential correlation of the disturbance terms across ideas for the same user, the robust standard error is clustered at users' level (Cameron $\&$ Miller, 2015). The software Stata 14.0 is used for econometric analysis. To reduce possible noise, this study drops the observations with ideas submitted within the first five days after registration, because these ideas might be the result of other factors such as curiosity rather than being inspired by interactions with peers, which departs too much from the conjecture in this study. Table 4 displays the main results. This paper also reports the results for the full sample in Table A1 (see Appendix A), which shows similar results as those in Table 4.

In Table 4, model 1 shows a positive relationship with statistical significance between the number of social ties (Ntie) and innovation performance for one idea $(\beta=0.008, \mathrm{p}=0.015)$. Given the marginal effect, if a user has one more social tie, the supports for his/her ideas may increase by 1.634 on average. This is in line with other researchers, who also reported the positive effect of online social ties (Burke et al., 2011; Ellison et al., 2014). Thus, H1 is supported.

We further explore the effect of quality ties by adding the share of quality ties (SQtie) in model 2 . The result shows the coefficient for SQtie is significantly positive $(\beta=0.797, \mathrm{p}=0.003)$. Holding other factors constant, this means the user innovation performance would increase by $7.97 \%$ if the share of quality social ties increases by $1 \%$. Thus, $\mathrm{H} 2$ is supported. This suggests the quality social ties can dramatically improve user innovation. Neglecting the quality of social ties may underestimate the effect of social relations on user innovation.

\section{Robustness Checks}

\section{Other Specification of Regression Model}

Other than the pooled regression in the main models of Table 4, this study also tries random effects estimations with both Poisson and OLS methods. The random effects estimation is usually used for 
Table 2. Description of Variables

\begin{tabular}{|c|c|c|}
\hline Variable & Notation & Description and Formula \\
\hline \multicolumn{3}{|l|}{ Dependent variable } \\
\hline Innovation performance & innovation & Number of supports one idea got \\
\hline \multicolumn{3}{|l|}{ Main Independent Variables } \\
\hline Quantity of social network relations & Ntie & Number of two-way "follow-up" ties one user has \\
\hline Quality of social network relations & SQtie & $\begin{array}{l}\text { Share of the quality ties over all social ties } \\
\text { SQtie }=\text { the number of quality ties/(Ntie }+1) *\end{array}$ \\
\hline \multicolumn{3}{|l|}{ Mediation Variables } \\
\hline emotional support & emotion & $\begin{array}{l}\text { Main measure: number of positive comments } \\
\text { Another measure: the total sentiment score }\end{array}$ \\
\hline information flow & infor & $\begin{array}{l}\text { Main measure: number of unique useful words in texts } \\
\text { Another measure: number of the unique noun words in texts }\end{array}$ \\
\hline \multicolumn{3}{|l|}{ Control Variables } \\
\hline \multicolumn{3}{|l|}{ User characteristics } \\
\hline Innovative experience & contributions & Number of ideas the user-contributed in the past \\
\hline Innovation level & highluser & $\begin{array}{l}\text { highluser }=1 \text { if one user is a high-level innovative user; } \\
\text { highluser }=0 \text { if one user isn't a high-level innovative user }\end{array}$ \\
\hline Social tendency & socializer & Number of Socializer Badges one user got \\
\hline Platform age & user_age & The user's platform age (month) \\
\hline \multicolumn{3}{|l|}{ Idea characteristics } \\
\hline No. of images & images & Number of images about the blocks model in idea page \\
\hline No. of idea's page views & views & Number of idea's page views $/ 1000$ \\
\hline Idea Age & idea_age & Number of days one idea receiving supports \\
\hline \multirow[t]{2}{*}{ Time trend } & month & time (month) to submit ideas \\
\hline & num & number of participants submitting ideas at that month \\
\hline
\end{tabular}

*Because some users do not have social ties at all (Ntie=0), this paper sets the denominator to $(\mathrm{Ntie}+1)$.

panel data analysis, but also can be used for the cluster sample as in this study (Wooldridge, 2009). The results of Table 5 show that the quality of social ties (SQtie) positively influence innovation performance, while the effect of the ties' number on innovation performance becomes insignificant when adding SQtie in the regression. Therefore, this implies that though the innovation performance will increase with the number of social ties, what matters more is the increased quality of them.

\section{Falsification Test}

To check to which extent the result is driven by random factors, this paper follows Chetty et al. (2009) and conduct a falsification test. We randomly assign the quality of social ties (SQtie) to users to get a random sample and then run the main regression (Model 2 of Table 4). To increase the statistical power of the falsification test, we repeat this procedure 500 times and plot the distribution of the estimates in Figure 2.

The distribution of the "placebo" estimates from the random assignment sample is centered around zero with the mean of -0.0304 and the standard deviation of 0.4276 , while the benchmark estimate stands on the far-right side of the distribution. This suggests that there is a huge difference between the estimates from the true sample and the random samples. By simple calculation, the probability 
Table 3. Summary Statistics

\begin{tabular}{|c|c|c|c|c|}
\hline Variable & Mean & Standard Deviation & Minimum & Maximum \\
\hline innovation & 201.481 & 738.835 & 1 & 10,000 \\
\hline Ntie & 6.168 & 14.822 & 0 & 134 \\
\hline SQtie & 0.057 & 0.128 & 0 & 0.750 \\
\hline emotion(main) & 18.898 & 27.332 & 1 & 463 \\
\hline emotion(another) & 42.514 & 59.695 & 2 & 998 \\
\hline infor(main) & 79.085 & 97.437 & 5 & 1137 \\
\hline infor(another) & 31.769 & 42.214 & 2 & 528 \\
\hline contributions & 10.677 & 17.620 & 1 & 140 \\
\hline highluser & 0.083 & 0.276 & 0 & 1 \\
\hline socializer & 2.962 & 13.251 & 0 & 169 \\
\hline user_age & 18.375 & 15.350 & 1 & 75 \\
\hline images & 8.991 & 6.773 & 1 & 91 \\
\hline views & 3.125 & 20.801 & 0.003 & 1,000 \\
\hline idea_age & 125.761 & 122.987 & 1 & 497 \\
\hline month & 5.807 & 3.320 & 1 & 12 \\
\hline num & 246.928 & 55.438 & 64 & 356 \\
\hline No. of Ideas & \multicolumn{4}{|c|}{3,961} \\
\hline
\end{tabular}

that the benchmark estimate could be gotten by the random sample is about 2.68 percent. As a result, the null hypothesis that the benchmark estimate of Model 2 of Table 4 is driven by the random sample can be rejected with a very low probability to make mistake. Altogether, these mean that the positive and significant coefficient for the quality of social relationships cannot be solely driven by random factors. This greatly reduces the concern of the omitted variables problem.

\section{The Mediation Effects}

This section checks the mechanism of how user social network relations influence innovation. We collect the comments text for each idea, and employ the text mining technology (i.e., sentiment analysis and unique words extraction) to retrieve two mediators - emotional support \& information flow. Then, we use both stepwise regression (Baron \& Kenny, 1986) and bootstrap method (Wood, 2005 ) to test their mediation effects respectively.

\section{The Mediation Effect of "Emotional Support"}

Stepwise regression is generally adopted to test the mediation effect. Its general steps are: (1) test the effects of X on Y, (2) test the effect of X on the Mediator (the coefficient named by $a$ ), (3) test the effect of Mediator on $\mathrm{Y}$ with the control of X (the coefficient named by $b$ ). If both the coefficient $a$ and $b$ are statistically significant, so does the mediation effect $\left(a^{*} b\right)$, i.e., the mediation effect is verified. Given that both the quantity and quality of social ties $(X)$ have significant effects on innovation performance (Y) in the previous part, then the (2) and (3) steps are completed.

Table 6 shows the OLS regression results for the two steps to test the mediation effect of "emotional support". The results are sufficient to support the mediation effect no matter whether we use the main measure or alternative measure for emotion inspiration. Moreover, we also generate a bootstrap confidence interval for the mediation effect $\left(a^{*} b\right)$ with 1,000 bootstrap samples. Table 7 
Table 4. The Effect of Social Ties on Innovation Performance

\begin{tabular}{|c|c|c|c|c|}
\hline \multirow[t]{2}{*}{ Variable } & \multicolumn{2}{|c|}{ Model 1} & \multicolumn{2}{|c|}{ Model 2} \\
\hline & Coefficient & Margin & Coefficient & Margin \\
\hline \multirow[t]{2}{*}{ Ntie } & $0.008 * *$ & $1.634 * *$ & $0.007 * *$ & $1.433 * *$ \\
\hline & $(0.003)$ & $(0.695)$ & $(0.003)$ & $(0.689)$ \\
\hline \multirow[t]{2}{*}{ SQtie } & & & $0.797 * * *$ & $171.344 * * *$ \\
\hline & & & $(0.272)$ & $(59.767)$ \\
\hline \multirow[t]{2}{*}{ contributions } & $-0.017 * * *$ & $-3.563 * * *$ & $-0.017 * * *$ & $-3.589 * * *$ \\
\hline & $(0.003)$ & $(0.832)$ & $(0.004)$ & $(0.849)$ \\
\hline \multirow[t]{2}{*}{ highluser } & $1.606 * * *$ & $345.166^{* * *}$ & $1.530 * * *$ & $328.848 * * *$ \\
\hline & $(0.137)$ & (41.118) & $(0.134)$ & (38.816) \\
\hline \multirow[t]{2}{*}{ socializer } & 0.002 & 0.386 & 0.003 & 0.632 \\
\hline & $(0.005)$ & (1.013) & $(0.005)$ & $(1.005)$ \\
\hline \multirow[t]{2}{*}{ user_age } & $0.007 * *$ & $1.572 * *$ & $0.008 * *$ & $1.621 * *$ \\
\hline & $(0.004)$ & $(0.786)$ & $(0.003)$ & $(0.782)$ \\
\hline \multirow[t]{2}{*}{ images } & 0.006 & 1.232 & $0.008 * *$ & $1.670 * *$ \\
\hline & $(0.004)$ & $(0.763)$ & $(0.004)$ & $(0.771)$ \\
\hline \multirow[t]{2}{*}{ views } & $0.006 * * *$ & $1.307 * * *$ & $0.006^{* * *}$ & $1.317 * * *$ \\
\hline & $(0.001)$ & $(0.177)$ & $(0.001)$ & $(0.169)$ \\
\hline \multirow[t]{2}{*}{ idea_age } & $0.006^{* * *}$ & $1.378 * * *$ & $0.006^{* * *}$ & $1.349 * * *$ \\
\hline & $(0.001)$ & $(0.128)$ & $(0.001)$ & $(0.126)$ \\
\hline \multirow[t]{2}{*}{ Constant } & $2.387 * * *$ & & $2.367 * * *$ & \\
\hline & $(0.659)$ & & $(0.632)$ & \\
\hline Time trend & Controlled & & Controlled & \\
\hline No. of observations & 3,409 & & 3,409 & \\
\hline No. of clusters/users & 1,545 & & 1,545 & \\
\hline
\end{tabular}

Notes: Robust standard errors clustered at the user level are reported in the parentheses. ${ }^{* * *}$ Significant at the $1 \%$ level; ** Significant at the $5 \%$ level; * Significant at the $10 \%$ level.

Table 5. The Result of Random Effects Estimate

\begin{tabular}{|c|c|c|c|c|}
\hline Variable & OLS & OLS & Poisson & Poisson \\
\hline Ntie & $1.957^{*}$ & 1.395 & $0.004^{* *}$ & 0.002 \\
\hline SQtie & $(1.131)$ & $(1.173)$ & $(0.002)$ & $(0.002)$ \\
\hline & & $321.334^{* *}$ & & $\left(0.778^{* * *}\right.$ \\
\hline Control variables & Yes & $(153.334)$ & Yes & Yes \\
\hline No. of observations & 3,409 & Yes & 3,409 & 3,409 \\
\hline No. of users & 1,545 & 3,409 & 1,545 & 1,545 \\
\hline
\end{tabular}

Notes: Robust standard errors are reported in the parentheses. ${ }^{* * *}$ Significant at the $1 \%$ level; ${ }^{* *}$ Significant at the $5 \%$ level; * Significant at the $10 \%$ level. 
Figure 2. Distribution of Estimated "Social Ties Quality" Coefficients of Falsification Test (Note: The figure shows the probability density distribution of the estimated coefficients, which are from $\mathbf{5 0 0}$ simulations randomly assigning the quality of social relationships to users. The vertical line presents the coefficients of Model 2 of Table 4.)

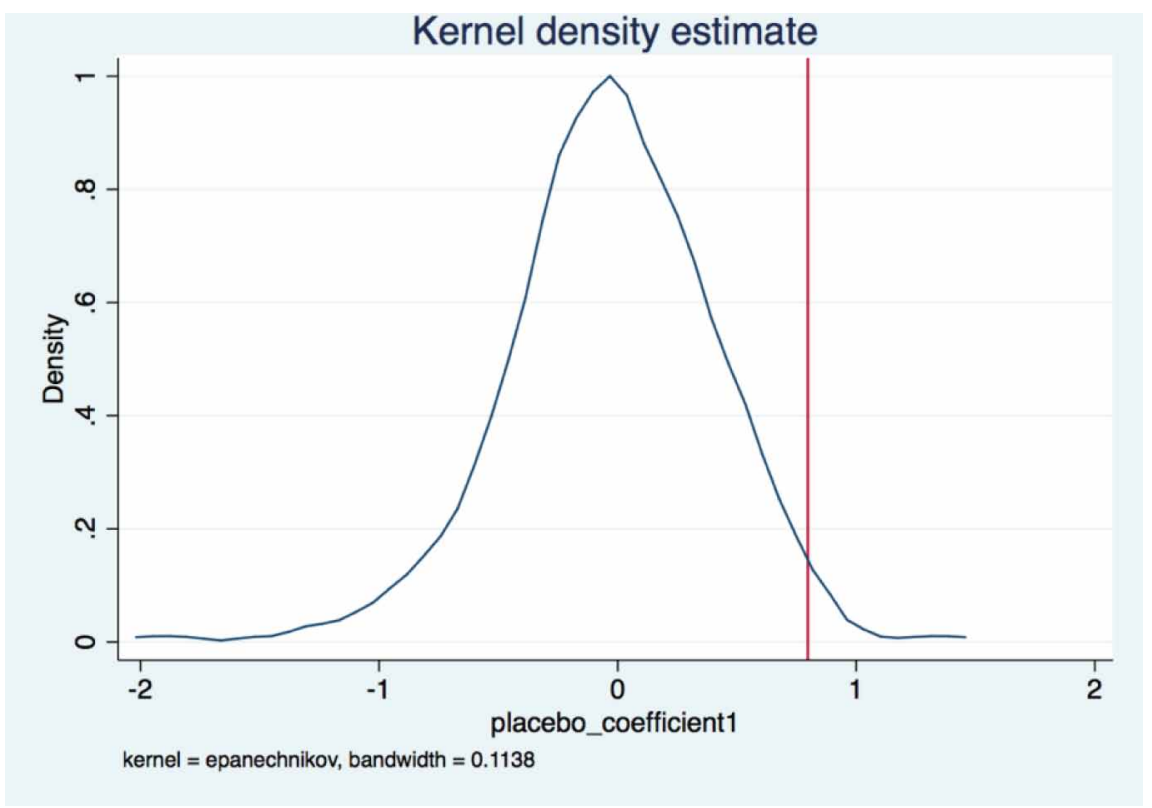

shows that the $95 \%$ Confidence Interval excludes 0 , which also supports the mediation effect. Overall, results from stepwise regression and bootstrap method illustrate that the quantity (Ntie) and quality (SQtie) of social ties influence innovation outcomes through the path of emotional support. Thus, $\mathrm{H} 3 \mathrm{a}$ and $\mathrm{H} 3 \mathrm{~b}$ get supported.

\section{The Mediation Effect of "Information Flow"}

Table 8 and Table 9 replicate the results in Table 6 and Table 7 for the mediation effect of information flow, respectively. The results illustrate that the quality of social ties (SQtie) dramatically influences innovation outcome through the path of information flow, while the ties' quantity (Ntie) exerts tiny or even no significant influence. The number of social ties fails to induce more useful innovative information with the presence of the share of quality social ties. Thus, the evidence is sufficient to support $\mathrm{H} 4 \mathrm{~b}$ but not $\mathrm{H} 4 \mathrm{a}$. This means that insightful information to generate a good idea comes mostly from quality ties, i.e., high-level innovators.

\section{DISCUSSION}

To explore how online social network relations influence users' innovation outcomes, this paper crawls the public data of users' interactions on the LEGO Ideas platform to build the user social network. Through Possion regression, this paper firstly checks the impact of social network relation on user innovation from both quantity and quality dimensions. Secondly, this paper tests the mediation effects of emotional support \& information flow. Two main findings are verified.

Firstly, apart from the quantity of social ties, the quality of social ties can also significantly influence the user innovation performance. This study pays more attention to the quality perspective of users' online relations, i.e., the interactions with high-lever innovators, which is often neglected by previous studies. The empirical results show that the quality of users' social ties can dramatically 
Table 6. The Mediation Effect of Emotional Support

\begin{tabular}{|c|c|c|c|c|}
\hline \multirow{2}{*}{ Variable } & \multicolumn{2}{|c|}{ Main Measure for emotion } & \multicolumn{2}{c|}{ Another Measure for emotion } \\
\cline { 2 - 5 } & $\begin{array}{c}\text { Step 2 } \\
\text { X->Med }\end{array}$ & $\begin{array}{c}\text { Step3 } \\
\text { X+Med->Y }\end{array}$ & $\begin{array}{c}\text { Step 2 } \\
\text { X->Med }\end{array}$ & $\begin{array}{c}\text { Step3 } \\
\text { X+Med->Y }\end{array}$ \\
\hline Ntie & $0.092^{* *}$ & -0.269 & $0.198^{* *}$ & -0.234 \\
\hline SQtie & $(0.041)$ & $(0.699)$ & $(0.093)$ & $(0.709)$ \\
\hline & $11.390 *$ & 90.777 & $26.648^{*}$ & $(14.883$ \\
\hline emotion & $(6.030)$ & $(81.304)$ & $(13.607)$ & $9.019 * * *$ \\
\hline Control variables & & $19.705 * * *$ & & $(0.986)$ \\
\hline No. of observations & 3,409 & $(2.269)$ & Yes \\
\hline No. of clusters/users & 1,545 & 3,409 & 3,409 & 3,409 \\
\hline R-squared & 0.534 & 0.836 & 1,545 & 1,545 \\
\hline
\end{tabular}

Notes: Robust standard errors clustered at the user level are reported in the parentheses. ${ }^{* * *}$ Significant at the $1 \%$ level; ** Significant at the $5 \%$ level; * Significant at the $10 \%$ level.

Table 7. Bootstrap Confidence Interval for the Mediation of Emotional Support

\begin{tabular}{|c|c|c|c|c|c|c|}
\hline & Mediation Model & $\begin{array}{c}\text { Bootstrap } \\
\text { Coefficient }\left(a^{*} b\right)\end{array}$ & $\begin{array}{c}\text { Bootstrap } \\
\text { SD }\end{array}$ & $\mathbf{z}$ & $\mathbf{p}>|\mathbf{z}|$ & $\begin{array}{c}\text { 95\% Confidence } \\
\text { Interval }\end{array}$ \\
\hline $\begin{array}{c}\text { Main } \\
\text { measure } \\
\text { for } \\
\text { emotion }\end{array}$ & Ntie $\rightarrow$ emotion $\rightarrow$ innovation & 1.818 & 0.679 & 2.68 & 0.007 & $(0.487,3.148)$ \\
\cline { 2 - 7 } & SQtie $\rightarrow$ emotion $\rightarrow$ innovation & 224.433 & 106.525 & 2.11 & 0.035 & $\begin{array}{c}(15.649, \\
433.218)\end{array}$ \\
\hline $\begin{array}{c}\text { Another } \\
\text { measure } \\
\text { for } \\
\text { emotion }\end{array}$ & Ntie $\rightarrow$ emotion $\rightarrow$ innovation & 1.783 & 0.694 & 2.57 & 0.010 & $(0.423,3.142)$ \\
\cline { 2 - 7 } & SQtie $\rightarrow$ emotion $\rightarrow$ innovation & 240.327 & 110.320 & 2.18 & 0.029 & $\begin{array}{c}(24.104, \\
456.551)\end{array}$ \\
\hline
\end{tabular}

induce a positive effect on user innovation when controlling the total number of social ties. And two robustness checks provide more evidence for this effect.

Secondly, users' social network relations influence user innovation through both the paths of emotional support \& information flow. On the one hand, the emotional support from others can stimulate them to enhance their innovation aspiration. More online social relations or with higher quality often bring more emotional support for users. On the other hand, the information shared from other users can also help them to improve their innovative outcomes. The empirical results show that the quality of social relations, rather than the quantity, depends the usefulness of information flow from others. This implies valuable information comes mostly from the ties with high-level innovators. The transmission of innovative knowledge from high-level users to the focal user is essential to optimize the total outcome on the online platform.

\section{CONTRIBUTIONS AND IMPLICATIONS}

This study provides contribution in several aspects. First, it offers complementary insights to previous studies on the effects of users' social relations on innovation (e.g., Wasko \& Faraj, 2005; 
Table 8. The Mediation Effect of Information Flow

\begin{tabular}{|c|c|c|c|c|}
\hline \multirow{2}{*}{ Variable } & \multicolumn{2}{|c|}{ Main Measure for infor } & \multicolumn{2}{c|}{ Another Measure for infor } \\
\cline { 2 - 5 } & $\begin{array}{c}\text { Step 2 } \\
\text { X->Med }\end{array}$ & $\begin{array}{c}\text { Step3 } \\
\text { X+Med->Y }\end{array}$ & $\begin{array}{c}\text { Step 2 } \\
\text { X->Med }\end{array}$ & $\begin{array}{c}\text { Step3 } \\
\text { X+Med->Y }\end{array}$ \\
\hline Ntie & 0.196 & 0.496 & $0.093^{*}$ & 0.404 \\
\hline SQtie & $(0.124)$ & $(0.804)$ & $(0.056)$ & $(0.771)$ \\
\hline infor & $38.970 * *$ & 105.931 & $17.991 * *$ & 93.362 \\
\hline Control variables & $(17.765)$ & $(100.696)$ & $(7.818)$ & $(99.231)$ \\
\hline No. of observations & & $5.370 * * *$ & & $12.331 * * *$ \\
\hline No. of clusters/users & 1,409 & $(0.657)$ & & Yes \\
\hline R-squared & 0.610 & Yes & 3,409 & $3,522)$ \\
\hline
\end{tabular}

Notes: Robust standard errors clustered at the user level are reported in the parentheses. ${ }^{* *}$ Significant at the $1 \%$ level; ${ }^{* *}$ Significant at the $5 \%$ level; * Significant at the $10 \%$ level.

Table 9. Bootstrap Confidence Interval for the Mediation of Information Flow

\begin{tabular}{|c|c|c|c|c|c|c|}
\hline & Mediation Model & $\begin{array}{c}\text { Bootstrap } \\
\text { Coefficient }\left(a^{*} b\right)\end{array}$ & $\begin{array}{c}\text { Bootstrap } \\
\text { SD }\end{array}$ & $\mathbf{z}$ & $\mathbf{p}>\mid \mathbf{z l}$ & $\begin{array}{c}\text { 95\% Confidence } \\
\text { Interval }\end{array}$ \\
\hline \multirow{2}{*}{$\begin{array}{c}\text { Main } \\
\text { measure for } \\
\text { infor }\end{array}$} & Ntie $\rightarrow$ infor $\rightarrow$ innovation & 1.052 & 0.559 & 1.88 & 0.070 & $(-0.0423,2.147)$ \\
\cline { 2 - 7 } & SQtie $\rightarrow$ infor $\rightarrow$ innovation & 209.280 & 92.224 & 2.27 & 0.023 & $\begin{array}{c}(28.524, \\
390.036)\end{array}$ \\
\hline $\begin{array}{c}\text { Another } \\
\text { measure for } \\
\text { infor }\end{array}$ & Ntie $\rightarrow$ infor $\rightarrow$ innovation & 1.145 & 0.584 & 1.96 & 0.050 & $(0.001,2.289)$ \\
\cline { 2 - 7 } & SQtie $\rightarrow$ infor $\rightarrow$ innovation & 221.849 & 94.758 & 2.34 & 0.019 & $\begin{array}{c}(36.125, \\
407.571)\end{array}$ \\
\hline
\end{tabular}

Trier, 2008; Chen et al., 2012). Specially, we build the social network to measure the users' online relations multi-dimensionally (i.e., quantity \& quality). Apart from the quantity of social network relations, we identify another important dimension of these relations in the virtual innovation platform - the quality. Moreover, the quantity and quality of social network relations play different roles in influencing user innovation outcomes. This gives theoretical evidence of considering the quality of social relations to future studies.

Second, this paper examines two paths of how social network relations influence user innovation performance (i.e., emotional support \& information flow). Through analyzing the users' interaction content (i.e., the textual comments), we find two kinds of useful resources in user interaction emotional support and useful information, which mediate the effects of online relations on user innovation. We also compare the difference of influencing paths between the quantity and quality of social network relations. It finds that both the quantity and quality of social network relations could help users gain more positive emotions, while only these relations' quality could facilitate the inflow of more useful information and knowledge. Many studies claimed that users' online relations can improve their innovation by bringing diverse and useful information through interaction (e.g., Chan et al., 2015; Imran Muhammad, 2019). This study extends this literature and finds what actually bring useful information is the quality ties. 
Additionally, this paper also proposes the practical implications for virtual innovation platforms to improve their innovation performance. For these platforms, a useful method to bring more better ideas is to enhance the interactions between users. For example, platforms can design more intriguing social interaction schemes (e.g., the use of Emoji, instant messenger) to enhance the emotional support and stimulate knowledge sharing among users (e.g., the comments and replies attached to one idea, innovation experiences sharing in videos). Besides, platforms should stimulate more relations and interactions between excellent innovators and others, which would facilitate the transfer of valuable innovation to more users. For example, platforms can formulate incentive policies to reward highlevel innovators who actively interact with others.

\section{CONCLUSION}

To summarize, this study investigates how online users' social network relations improve innovation outcomes in the context of virtual innovation platforms. We find that both the quantity and the quality of the online relations have significant effects on user innovation but in different ways. The increased number of online relations brings the users more positive emotions, while the quality social relations bring them more useful information and knowledge. In short, more and better online interactive relations induce better user innovation performance. This paper has, of course, its own limitation. Our analysis involves only one user innovation platform of the LEGO Ideas, and the collected data is essentially cross-sectional. It is a good starting point, yet more work needs to be done in other contextualized user innovation platforms. Moreover, the current framework can also be extended to test the dynamic effects of user social network on innovation outcomes over time, if the virtual platforms allow the collection of panel data.

\section{ACKNOWLEDGMENT}

This research was supported by the National Natural Science Foundation of China [grant numbers 71572097, 71773019]; the Shandong Provincial Natural Science Foundation of China [grant number ZR2019BG004]; and the Humanity and Social Science Youth Foundation of Ministry of Education of China [grant number 19YJC630094]. 


\section{REFERENCES}

Akcigit, U., Caicedo, S., Miguelez, E., Stantcheva, S., \& Sterzi, V. (2018). Dancing with the stars: Innovation through interactions. National Bureau of Economic Research Working Paper Series, No. 24466.

Amabile, T. M., Barsade, S. G., Mueller, J. S., \& Staw, B. M. (2005). Affect and creativity at work. Administrative Science Quarterly, 50(3), 367-403. doi:10.2189/asqu.2005.50.3.367

Amar, A. D., \& Juneja, J. A. (2008). A descriptive model of innovation and creativity in organizations: A synthesis of research and practice. Knowledge Management Research and Practice, 6(4), 298-311. doi:10.1057/ kmrp.2008.18

Baldus, B. J., Voorhees, C., \& Calantone, R. (2015). Online brand community engagement: Scale development and validation. Journal of Business Research, 68(5), 978-985. doi:10.1016/j.jbusres.2014.09.035

Balka, K., Raasch, C., \& Herstatt, C. (2014). The effect of selective openness on value creation in user innovation communities. Journal of Product Innovation Management, 31(2), 392-407. doi:10.1111/jpim.12102

Baron, R. M., \& Kenny, D. A. (1986). The moderator-mediator variable distinction in social psychological research: Conceptual, strategic, and statistical considerations. Journal of Personality and Social Psychology, 51(6), 1173-1182. doi:10.1037/0022-3514.51.6.1173 PMID:3806354

Blohm, I., Bretschneider, U., Leimeister, J. M., \& Krcmar, H. (2011). Does collaboration among participants lead to better ideas in it-based idea competitions? An empirical investigation. International Journal of Networking \& Virtual Organisations, 9(2), 106-122. doi:10.1504/IJNVO.2011.042413

Bulgurcu, B., Van Osch, W., \& Kane, G. C. (2018). The rise of the promoters: User classes and contribution patterns in enterprise social media. Journal of Management Information Systems, 35(2), 610-646. doi:10.108 0/07421222.2018.1451960

Burke, M., Kraut, R., \& Marlow, C. (2011). Social capital on facebook: Differentiating uses and users. Paper presented at the SIGCHI Conference on Human Factors in Computing Systems, Vancouver, BC, Canada. doi:10.1145/1978942.1979023

Cameron, A. C., \& Miller, D. L. (2015). A practitioner's guide to cluster-robust inference. The Journal of Human Resources, 50(2), 317-372. doi:10.3368/jhr.50.2.317

Černe, M., Nerstad, C. G. L., Dysvik, A., \& Škerlavaj, M. (2014). What goes around comes around: Knowledge hiding, perceived motivational climate, and creativity. Social Science Electronic Publishing, 57(1), 172-192.

Chan, K. W., Li, S. Y., \& Zhu, J. J. (2015). Fostering customer ideation in crowdsourcing community: The role of peer-to-peer and peer-to-firm interactions. Journal of Interactive Marketing, 31, 42-62. doi:10.1016/j. intmar.2015.05.003

Chen, L., Marsden, J. R., \& Zhang, Z. (2012). Theory and analysis of company-sponsored value co-creation. Journal of Management Information Systems, 29(2), 141-172. doi:10.2753/MIS0742-1222290206

Chetty, R., Looney, A., \& Kroft, K. (2009). Salience and taxation: Theory and evidence. The American Economic Review, 99(4), 1145-1177. doi:10.1257/aer.99.4.1145

Chiu, C.-M., Hsu, M.-H., \& Wang, E. T. G. (2006). Understanding knowledge sharing in virtual communities: An integration of social capital and social cognitive theories. Decision Support Systems, 42(3), 1872-1888. doi:10.1016/j.dss.2006.04.001

Choi, J. N., Sung, S. Y., Lee, K., \& Cho, D.-S. (2011). Balancing cognition and emotion: Innovation implementation as a function of cognitive appraisal and emotional reactions toward innovation. Journal of Organizational Behavior, 32(1), 107-124. doi:10.1002/job.684

Cross, R., \& Cummings, J. N. (2004). Tie and network correlates of individual performance in knowledgeintensive work. Academy of Management Journal, 47(6), 928-937.

Ellison, N. B., Vitak, J., Gray, R., \& Lampe, C. (2014). Cultivating social resources on social network sites: Facebook relationship maintenance behaviors and their role in social capital processes. Journal of ComputerMediated Communication, 19(4), 855-870. doi:10.1111/jcc4.12078 
Ernst, M., \& Brem, A. (2017). Social media for identifying lead users? Insights into lead users' social media habits. International Journal of Innovation and Technology Management, 14(04), 1-21. doi:10.1142/ S0219877017500225

Fowler, J. H., \& Christakis, N. A. (2010). Cooperative behavior cascades in human social networks. Proceedings of the National Academy of Sciences of the United States of America, 107(12), 5334-5338. doi:10.1073/ pnas.0913149107 PMID:20212120

Fredrickson, B. L. (2004). The broaden-and-build theory of positive emotions. Philosophical Transactions of the Royal Society of London. Series B, Biological Sciences, 359(1449), 1367-1377. doi:10.1098/rstb.2004.1512 PMID: 15347528

Frey, K., Lüthje, C., \& Haag, S. (2011). Whom should firms attract to open innovation platforms? The role of knowledge diversity and motivation. Long Range Planning, 44(5), 397-420. doi:10.1016/j.lrp.2011.09.006

Gharib, R. K., Philpott, E., \& Duan, Y. (2017). Factors affecting active participation in b2b online communities: An empirical investigation. Information \& Management, 54(4), 516-530. doi:10.1016/j.im.2016.11.004

Goes, P. B., Lin, M., \& Au Yeung, C. (2014). "Popularity effect" in user-generated content: Evidence from online product reviews. Information Systems Research, 25(2), 222-238. doi:10.1287/isre.2013.0512

Granovetter, M. S. (1973). The strength of weak ties. American Journal of Sociology, 78(6), 1360-1380. doi: $10.1086 / 225469$

Guo, W., Liang, R. Y., Wang, L., \& Peng, W. (2017). Exploring sustained participation in firm-hosted communities in china: The effects of social capital and active degree. Behaviour \& Information Technology, 36(3), $223-242$. doi:10.1080/0144929X.2016.1212402

Hassan, L., Dias, A., \& Hamari, J. (2019). How motivational feedback increases user's benefits and continued use: A study on gamification, quantified-self and social networking. International Journal of Information Management, 46, 151-162. doi:10.1016/j.ijinfomgt.2018.12.004

Hossain, M. (2017). Motivations, challenges, and opportunities of successful solvers on an innovation intermediary platform. Technological Forecasting and Social Change, 128, 67-73. doi:10.1016/j.techfore.2017.10.018

Hossain, M., \& Islam, K. M. Z. (2015). Ideation through online open innovation platform: Dell ideastorm. Journal of the Knowledge Economy, 6(3), 1-14. doi:10.1007/s13132-015-0262-7

Huang, C.-C., Lin, T.-C., \& Lin, K.-J. (2009). Factors affecting pass-along email intentions (paeis): Integrating the social capital and social cognition theories. Electronic Commerce Research and Applications, 8(3), 160-169. doi:10.1016/j.elerap.2008.11.001

Huang, Y., Singh, P. V., \& Srinivasan, K. (2014). Crowdsourcing new product ideas under consumer learning. Management Science, 60(9), 2138-2159. doi:10.1287/mnsc.2013.1879

Hwang, E. H., Singh, P. V., \& Argote, L. (2019). Jack of all, master of some: Information network and innovation in crowdsourcing communities. Information Systems Research, 30(2), 389-410. doi:10.1287/isre.2018.0804

Imran Muhammad, K. (2019). Does social media promote knowledge exchange? A qualitative insight. Management Decision, 57(3), 688-702. doi:10.1108/MD-05-2017-0477

Islam, J. U., \& Rahman, Z. (2017). The impact of online brand community characteristics on customer engagement: An application of stimulus-organism-response paradigm. Telematics and Informatics, 34(4), 96-109. doi:10.1016/j.tele.2017.01.004

Jeppesen, L. B., \& Laursen, K. (2009). The role of lead users in knowledge sharing. Research Policy, 38(10), 1582-1589. doi:10.1016/j.respol.2009.09.002

Kane, G. C., Alavi, M., Labianca, G., \& Borgatti, S. P. (2014). What's different about social media networks? A framework and research agenda. Management Information Systems Quarterly, 38(1), 275-304. doi:10.25300/ MISQ/2014/38.1.13

Kilduff, M., \& Tsai, W. (2003). Socialnetworks and organizations. SAGE Publications. doi:10.4135/9781849209915 
Kohn, N. W., Paulus, P. B., \& Choi, Y. H. (2011). Building on the ideas of others: An examination of the idea combination process. Journal of Experimental Social Psychology, 47(3), 554-561. doi:10.1016/j.jesp.2011.01.004

Kosonen, M., Gan, C., Olander, H., \& Blomqvist, K. (2013). My idea is our idea! Supporting user-driven innovation activities in crowdsourcing communities. International Journal of Innovation Management, 17(03), 179-1690. doi:10.1142/S1363919613400100

Latané, B. (1981). The psychology of social impact. The American Psychologist, 36(4), 343-356. doi:10.1037/0003-066X.36.4.343

Lechner, C., Frankenberger, K., \& Floyd, S. W. (2010). Task contingencies in the curvilinear relationships between intergroup networks and initiative performance. Academy of Management Journal, 53(4), 865-889. doi: $10.5465 / \mathrm{amj} .2010 .52814620$

Li, M., Kankanhalli, A., \& Kim, S. H. (2016). Which ideas are more likely to be implemented in online user innovation communities? An empirical analysis. Decision Support Systems, 84, 28-40. doi:10.1016/j. dss.2016.01.004

Liang, Y., Zhou, R., Chen, J., \& Wei, K. (2016). The impact of power boundary management on the design of company-initiated open innovation platform. Paper presented at the PACIS.

Lin, K.-Y., \& Lu, H.-P. (2011). Intention to continue using facebook fan pages from the perspective of social capital theory. Cyberpsychology, Behavior, and Social Networking, 14(10), 565-570. doi:10.1089/cyber.2010.0472 PMID:21381968

Lin, N. (2002). Social capital: A theory of social structure and action (Vol. 19). Cambridge University Press.

Ma, J., Lu, Y., \& Gupta, S. (2019). User innovation evaluation: Empirical evidence from an online game community. Decision Support Systems, 117, 113-123. doi:10.1016/j.dss.2018.11.003

McFadyen, M. A., \& Cannella, A. A. Jr. (2004). Social capital and knowledge creation: Diminishing returns of the number and strength of exchange relationships. Academy of Management Journal, 47(5), 735-746.

Nahapiet, J., \& Ghoshal, S. (1998). Social capital, intellectual capital, and the organizational advantage. Academy of Management Review, 23(2), 242-266. doi:10.5465/amr.1998.533225

Pai, P., \& Tsai, H.-T. (2016). Reciprocity norms and information-sharing behavior in online consumption communities: An empirical investigation of antecedents and moderators. Information \& Management, 53(1), 38-52. doi:10.1016/j.im.2015.08.002

Pajo, S., Vandevenne, D., \& Duflou, J. R. (2017). Automated feature extraction from social media for systematic lead user identification. Technology Analysis and Strategic Management, 29(6), 642-654. doi:10.1080/09537 325.2016.1220517

Panagiotou, N., Katakis, I., \& Gunopulos, D. (2016). Detecting events in online social networks: Definitions, trends and challenges. In Solving large scale learning tasks. Challenges and algorithms (pp. 42-84). Springer. doi:10.1007/978-3-319-41706-6_2

Poria, S., Cambria, E., Howard, N., Huang, G.-B., \& Hussain, A. (2016). Fusing audio, visual and textual clues for sentiment analysis from multimodal content. Neurocomputing, 174, 50-59. doi:10.1016/j.neucom.2015.01.095

Rishika, R., \& Ramaprasad, J. (2019). The effects of asymmetric social ties, structural embeddedness, and tie strength on online content contribution behavior. Management Science, 65(7), 3398-3422. doi:10.1287/ mnsc. 2018.3087

Sapountzi, A., \& Psannis, K. E. (2018). Social networking data analysis tools \& challenges. Future Generation Computer Systems, 86, 893-913. doi:10.1016/j.future.2016.10.019

Stephen, A. T., Zubcsek, P. P., \& Goldenberg, J. (2016). Lower connectivity is better: The effects of network structure on redundancy of ideas and customer innovativeness in interdependent ideation tasks. JMR, Journal of Marketing Research, 53(2), 263-279. doi:10.1509/jmr.13.0127

Sun, Y., Liu, L., Peng, X., Dong, Y., \& Barnes, S. J. (2014). Understanding chinese users' continuance intention toward online social networks: An integrative theoretical model. Electronic Markets, 24(1), 57-66. doi:10.1007/ s12525-013-0131-9 
Tan, J., Zhang, H., \& Wang, L. (2015). Network closure or structural hole? The conditioning effects of networklevel social capital on innovation performance. Entrepreneurship Theory and Practice, 39(5), 1189-1212. doi:10.1111/etap.12102

Thelwall, M., Buckley, K., \& Paltoglou, G. (2012). Sentiment strength detection for the social web. Journal of the Association for Information Science and Technology, 63(1), 163-173.

Trier, M. (2008). Towards dynamic visualization for understanding evolution of digital communication networks. Information Systems Research, 19(3), 335-350. doi:10.1287/isre.1080.0191

Tsai, H. T., \& Bagozzi, R. P. (2014). Contribution behavior in virtual communities: Cognitive, emotional, and social influences. Management Information Systems Quarterly, 38(1), 143-164. doi:10.25300/MISQ/2014/38.1.07

Tsai, W., \& Ghoshal, S. (1998). Social capital and value creation: The role of intrafirm networks. Academy of Management Journal, 41(4), 464-476.

Van den Hooff, B., \& de Leeuw van Weenen, F. (2004). Committed to share: Commitment and cmc use as antecedents of knowledge sharing. Knowledge and Process Management, 11(1), 13-24. doi:10.1002/kpm.187

Vavliakis, K. N., Tzima, F. A., \& Mitkas, P. A. (2012). Event detection via lda for the mediaeval2012 sed task. Paper presented at the MediaEval.

Wasko, M. L., \& Faraj, S. (2005). Why should I share? Examining social capital and knowledge contribution in electronic networks of practice. Management Information Systems Quarterly, 29(1), 35-57. doi:10.2307/25148667

Wasserman, S., \& Faust, K. (1994). Social network analysis: Methods and applications. Cambridge University Press. doi:10.1017/CBO9780511815478

Williams, D. (2006). On and off the net: Scales for social capital in an online era. Journal of Computer-Mediated Communication, 11(2), 593-628. doi:10.1111/j.1083-6101.2006.00029.x

Wooldridge, J. M. (2009). Introductory econometrics: A modern approach (4th ed.). Cengage Learning.

Yang, X., \& Li, G. (2016). Factors influencing the popularity of customer-generated content in a companyhosted online co-creation community: A social capital perspective. Computers in Human Behavior, 64, 760-768. doi:10.1016/j.chb.2016.08.002

Yu, Y., Lin, H., Meng, J., \& Zhao, Z. (2016). Visual and textual sentiment analysis of a microblog using deep convolutional neural networks. Algorithms, 9(2), 41. doi:10.3390/a9020041

Yuan, F., \& Woodman, R. W. (2010). Innovative behavior in the workplace: The role of performance and image outcome expectations. Academy of Management Journal, 53(2), 323-342. doi:10.5465/amj.2010.49388995

Zhou, J., Shin, S. J., Brass, D. J., Choi, J., \& Zhang, Z. (2009). Social networks, personal values, and creativity: Evidence for curvilinear and interaction effects. The Journal of Applied Psychology, 94(6), 1544-1552. doi:10.1037/a0016285 PMID:19916661

Zhu, F., \& Zhang, X. (2010). Impact of online consumer reviews on sales: The moderating role of product and consumer characteristics. Journal of Marketing, 74(2), 133-148. doi:10.1509/jm.74.2.133

Zucker, L. G., Darby, M. R., Brewer, M. B., \& Peng, Y. (1995). Collaboration structure and information dilemmas in biotechnology: Organizational boundaries as trust production. National Bureau of Economic Research Working Paper Series, No. 5199.

\section{ENDNOTES}

The Python codes are available on request.

The Python codes are available on request. 


\section{APPENDIX A}

\section{The Method of Sentiment Score Calculation}

This study uses SentiStrength to calculate the sentiment score for each comment text and determine whether it is a positive comment. SentiStrength is a lexicon-based classifier that uses additional (nonlexical) linguistic information and rules to detect the sentiment strength in short informal English text (Thelwall et al., 2012). Academic researchers can get the free version from http://sentistrength. wlv.ac.uk.

Even short texts can contain both positive and negative sentiments. For each text, the SentiStrength output is two integers: 1 to 5 for positive sentiment strength and a separate score of 1 to 5 for negative sentiment strength. Here, 1 signifies no sentiment and 5 signifies strong sentiment of each type. For instance, a text with a score of 3,5 would contain moderate positive sentiment and strong negative sentiment. Then we calculate the overall sentiment score for each comment text, shown as Eq. (3):

sentiscore $_{i}=$ positivescore $_{i}-$ negativescore $_{i}$

If sentiscore $>0$, the $i^{\text {th }}$ comment expresses a positive emotion; if sentiscore $<0$, the $i^{\text {th }}$ comment expresses a negative emotion; if sentiscore ${ }_{i}=0$, the $i^{\text {th }}$ comment expresses a natural attitude.

\section{APPENDIX B}

\section{The Process of Extracting Unique Useful Words}

This study uses Python's NLTK package to extract unique useful words from comment texts. To illustrate each step we implement, the outputs of the steps are shown in the following two-column table on this example comment: If you could upload a new and improved version where it's connecting to something on the bottom so they don't go sliding around? Either way this is so cool to me because I love Subnautica.

Table 10. The Process of Extracting Unique Useful Words for Comment Texts

\begin{tabular}{|c|c|}
\hline Steps & Outputs for Example Comment \\
\hline $\begin{array}{l}\text { 1. Run a Python script invoking the } \\
\text { NLTK algorithm to perform sentence } \\
\text { segmentation. }\end{array}$ & $\begin{array}{l}\text { "If you could upload a new and improved version where it's connecting to } \\
\text { something on the bottom so they don't go sliding around?" } \\
\text { "Either way this is so cool to me because I love Subnautica." }\end{array}$ \\
\hline $\begin{array}{l}\text { 2. Remove punctuation and take } \\
\text { word segmentation. }\end{array}$ & $\begin{array}{l}\text { 'If', 'you', 'could', 'upload', 'a', 'new', 'and', 'improved', 'version', 'where', 'it', } \\
\text { 's', 'connecting', 'to', 'something', 'on', 'the', 'bottom', 'so', 'they', 'don', 't', 'go', } \\
\text { 'sliding', 'around' } \\
\text { 'Either', 'way', 'this', 'is', 'so', 'cool', 'to', 'me', 'because', 'I', 'love', 'Subnautica' }\end{array}$ \\
\hline $\begin{array}{l}\text { 3. Remove stopwords (meaningless } \\
\text { words) according to the Stopword } \\
\text { dictionary. }\end{array}$ & $\begin{array}{c}\text { 'could', 'upload', 'new', 'improved', 'version', 'connecting', 'something', } \\
\text { 'bottom', 'go', 'sliding', 'around' } \\
\text { 'either', 'way', 'cool', 'love', 'Subnautica' }\end{array}$ \\
\hline $\begin{array}{l}\text { 4. Stem extractions, removing the } \\
\text { affix to get the root of a word. }\end{array}$ & $\begin{array}{c}\text { 'could', 'upload', 'new', 'improv', 'version', 'connect', 'someth', 'bottom', 'go', } \\
\text { 'slide', 'around' } \\
\text { 'either', 'way', 'cool', 'love', 'Subnautica' }\end{array}$ \\
\hline 5. Remove duplicates. & $\begin{array}{l}\text { 'could', 'upload', 'new', 'improv', 'version', 'connect', 'someth', 'bottom', 'go', } \\
\text { 'slide', 'around', 'either', 'way', 'cool', 'love', 'Subnautica' }\end{array}$ \\
\hline
\end{tabular}

Note: When only extracting the unique noun words, add one step of tagging words and keeping nouns between the step 3 and 4 , the final output of unique noun words is "'version', 'someth', 'way', 'love', 'Subnautica"'. 


\section{APPENDIX C}

Table 11. The Effect of Social Ties on Innovation Performance for Full Sample

\begin{tabular}{|c|c|c|c|c|}
\hline \multirow[t]{2}{*}{ Variable } & \multicolumn{2}{|c|}{ Model 1} & \multicolumn{2}{|c|}{ Model 2} \\
\hline & Coefficient & Margin & Coefficient & Margin \\
\hline \multirow[t]{2}{*}{ Ntie } & $0.008 * *$ & $1.516^{* *}$ & $0.007 * *$ & $1.326^{* *}$ \\
\hline & $(0.003)$ & $(0.640)$ & $(0.003)$ & $(0.635)$ \\
\hline \multirow[t]{2}{*}{ SQtie } & & & $0.743 * * *$ & $149.651 * * *$ \\
\hline & & & $(0.266)$ & $(54.480)$ \\
\hline \multirow[t]{2}{*}{ contributions } & $-0.017 * * *$ & $-3.451 * * *$ & $-0.017 * * *$ & $-3.488 * * *$ \\
\hline & $(0.003)$ & $(0.787)$ & $(0.004)$ & $(0.805)$ \\
\hline \multirow[t]{2}{*}{ highluser } & $1.665 * * *$ & $335.412 * * *$ & $1.596 * * *$ & $321.527 * * *$ \\
\hline & $(0.144)$ & $(40.112)$ & $(0.144)$ & $(38.601)$ \\
\hline \multirow[t]{2}{*}{ socializer } & 0.002 & 0.306 & 0.003 & 0.532 \\
\hline & $(0.005)$ & $(0.947)$ & $(0.005)$ & $(0.941)$ \\
\hline \multirow[t]{2}{*}{ user_age } & $0.007 * *$ & $1.404 * *$ & $0.007 * *$ & $1.417 * *$ \\
\hline & $(0.003)$ & $(0.698)$ & $(0.003)$ & $(0.696)$ \\
\hline \multirow[t]{2}{*}{ images } & $0.007 *$ & $1.311^{*}$ & $0.008 * *$ & $1.657 * *$ \\
\hline & $(0.003)$ & $(0.688)$ & $(0.003)$ & $(0.692)$ \\
\hline \multirow[t]{2}{*}{ views } & $0.006 * * *$ & $1.198 * * *$ & $0.006 * * *$ & $1.206 * * *$ \\
\hline & $(0.001)$ & $(0.169)$ & $(0.001)$ & $(0.162)$ \\
\hline \multirow[t]{2}{*}{ idea_age } & $0.006 * * *$ & $1.230 * * *$ & $0.006 * * *$ & $1.203 * * *$ \\
\hline & $(0.001)$ & $(0.121)$ & $(0.001)$ & $(0.119)$ \\
\hline \multirow[t]{2}{*}{ Constant } & $2.463 * * *$ & & $2.466 * * *$ & \\
\hline & $(0.603)$ & & $(0.575)$ & \\
\hline Time trend & Controlled & & Controlled & \\
\hline No. of observations & 3,961 & & 3,961 & \\
\hline
\end{tabular}

Notes: Robust standard errors clustered at the user level are reported in the parentheses. ${ }^{* *}$ Significant at the $1 \%$ level; ** Significant at the $5 \%$ level; * Significant at the $10 \%$ level. 
Guijie Qi is a professor of Information Systems in School of Management at Shandong University, China. He obtained a Ph.D. from Shandong University. He was a visiting scholar at the Chinese University of Hong Kong. He has a deep research in management information system and system theory, management decision, open innovation-based Web platform. His research has been published and presented internationally.

Linke Hou is a professor in the Center for Economic Research at Shandong University, China. He obtained a Ph.D. from University of Science and Technology of China. His fields of research are industrial organization theory and development economics. His paper has been published in Governance, Symmetry, and Computers, Journal of Computer and Communications among others. He lectures on organizational industry, empirical method of Econometrics.

Jiali Chen is a Lecturer of Information Systems in School of Management Engineering at Shandong Jianzhu University, China. She obtained a Ph.D. from Shandong University. Her research interests include online social network, big data analysis, online user behavior. Her paper has appeared in several journals and conferences of information systems, such as PACIS and CNAIS.

Yikai Liang is a lecturer in School of Management Science and Engineering at Shandong University of Finance and Economics, China. He received his Ph.D. in Management Science and Engineering from Shandong University, China. His research interests include e-Government, cloud computing, IT/IS innovation adoption and open government data. His paper has appeared in several journals and conferences of information systems such as GIQ, PACIS and CNAIS.

Qi Zhang is an associate professor at School of Economics, Fudan University. His research interests cover development economics, industrial innovation, and developmental institutions. 